\title{
Congenital diaphragmatic hernia: impact of prostanoids in the perioperative period
}

\author{
A P Bos, D Tibboel, F W J Hazebroek, T Stijnen, J C Molenaar
}

\begin{abstract}
A prospective study of 10 neonates with congenital diaphragmatic hernia and five controls to determine the importance of prostanoid concentrations perioperatively and the relation with persistent pulmonary hypertension (PPH) is reported. In neonates with congenital diaphragmatic hernia postoperative concentrations of the vasoconstrictor thromboxane $B_{2}$ rose significantly and were higher during episodes of PPH; this rise may provoke PPH and subsequent right to left shunting.
\end{abstract}

The outcome in patients with congenital diaphragmatic hernia depends either on the gravity of pulmonary hypoplasia or on the combination of pulmonary hypoplasia with persistent pulmonary hypertension (PPH). ${ }^{1}$

Degradation products of arachidonic acid such as the leukotrienes ${ }^{2}$ and the prostaglandins and thromboxanes (the so called prostanoids) have been associated with the generation of PPH in neonates. ${ }^{3}$

The purpose of this prospective study was to determine the importance of prostanoid concentrations and ventilatory variables in patients with congenital diaphragmatic hernia with and without PPH in the perioperative period.

Patients and methods

During the study period, December 1987 to February 1989, 10 consecutive neonates with congenital diaphragmatic hernia (mean gestational age $37 \cdot 6$ weeks, birth weight $3050 \mathrm{~g}$ ) were admitted to the paediatric surgical intensive care unit, because of severe respiratory insufficiency within six hours after birth.

During the same study period five patients with oesophageal atresia (mean gestational age 36 weeks, birth weight $2645 \mathrm{~g}$ ) served as a control group and they followed the same protocol.

Registration of ventilatory variables was carried out on admission, one hour before surgery, and one and six hours after surgery. These variables included the alveolar arterial oxygen differences $\left(\mathrm{AaDO}_{2}\right)$, mean airway pressure, oxygenation index, and ventilation index. ${ }^{4}$

Determination of thromboxane $B_{2}$, a stable metabolite of the vasocontrictor thromboxane $A_{2}$, and 6-keto-prostaglandin $F_{1 \alpha}(P g F)$, a stable metabolite of the vasodilator prostacycline, were analysed by radioimmunoassay.

The diagnosis of PPH was confirmed with the following diagnostic procedures: (i) hyperoxic hyperventilation test in which the arterial oxygen pressure $\left(\mathrm{PaO}_{2}\right)$ increased to $>13.3 \mathrm{kPa}$ after hyperventilation with $100 \%$ oxygen; (ii) preductal and postductal $\mathrm{PaO}_{2}$ differential of $>2 \cdot 7$ $\mathrm{kPa}$ considered evidence of a transductal shunt; and (iii) positive contrast echocardiography showing right to left shunting.

As the distributions of most variables were highly skewed the median and range were used as descriptive statistics in the statistical analysis.

\section{Results}

Ten patients with congenital diaphragmatic hernia and five controls were examined. Two of the patients had a right sided defect and eight had a left sided defect, two had never had surgery because their condition deteriorated rapidly. These two patients died at 15 and 25 hours after admission and necropsy confirmed severe lung hypoplasia. A third patient did not undergo surgery because he had an isoelectric electroencephalogram after a prolonged period of hypoxia immediately after birth. One of the seven patients who underwent surgery had trisomy 18 and died. All five control patients were operated on. One prematurely born infant died after severe intracranial haemorrhage.

In patients with congenital diaphragmatic hernia median concentration of thromboxane $B_{2}$ rose significantly from 250 (range 81-703) $\mathrm{pmol} / \mathrm{ml}$ preoperatively to 740 (range 443-1030) $\mathrm{pmol} / \mathrm{ml}$ postoperatively (signed rank test, $\mathrm{p}=0.018$ ). In the control group concentrations of thromboxane $B_{2}$ were 376 (range 250-497) $\mathrm{pmol} / \mathrm{ml}$ preoperatively and 185 (range $50-1010$ ) $\mathrm{pmol} / \mathrm{ml}$ postoperatively $(\mathrm{p}=0 \cdot 7)$. Plasma concentrations of $\mathrm{PgF}$, increased from 260 (range $140-8835$ ) to 2460 (range $1709-4150) \mathrm{pmol} / \mathrm{ml}$ in patients with congenital diaphragmatic hernia and from 455 (range 30-986) to 1145 (range $180-3682) \mathrm{pmol} / \mathrm{ml}$ in control patients; this was not significant. The increased concentrations of

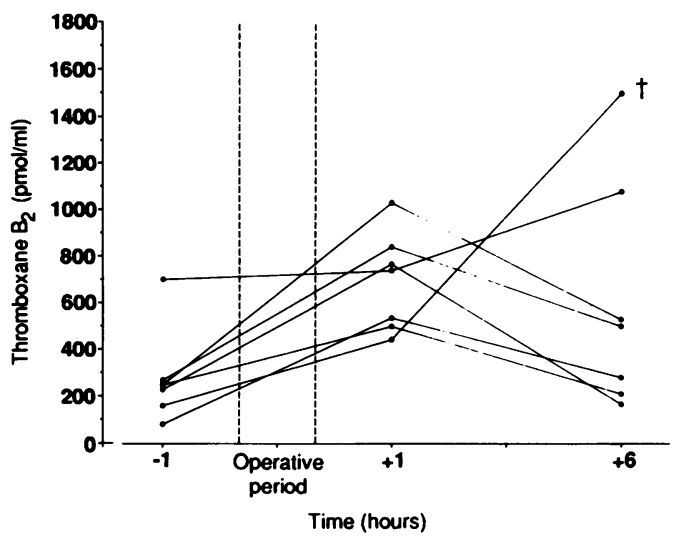

Concentrations of thromboxane $B_{2}$ before, immediately after, and six hours after surgery in seven patients with congenital diaphragmatic hernia. tPatient died.

Accepted 1 June 1990

(Arch Dis Child 1990;65:994-5). 
Median (range) ventilatory variables and prostanoid concentrations in patients with congenital diaphragmatic hernia with and without PPH

\begin{tabular}{lccc}
\hline & $\begin{array}{l}\text { Congenital diaphragmatic } \\
\text { hermia without } P P H\end{array}$ & $\begin{array}{l}\text { Congenital diaphragmatic } \\
\text { hermia with PPH }\end{array}$ & $p$ Value \\
\hline $\mathrm{AaDO}_{2}$ & $201(127-385)$ & $559(318-623)$ & $0 \cdot 016$ \\
Mean airway pressure & $11(6-13)$ & $9(8-15)$ & $0 \cdot 9$ \\
Oxygenation index & $4(2-10)$ & $21(8-30)$ & $0 \cdot 016$ \\
Ventilation index & $630(330-1296)$ & $542(497-1138)$ & $0 \cdot 8$ \\
Thromboxane $\mathrm{B}_{2}$ (pmol/ml) & $312(262-656)$ & $774(477-3699)$ & 0.03 \\
PgF (pmol/ml) & $726(562-1056)$ & $938(55-2713)$ & 0.3 \\
\hline
\end{tabular}

thromboxane $B_{2}$ at one hour postoperatively dropped to preoperative concentrations in all but two patients with congenital diaphragmatic hernia (figure). One of these patients died with high concentrations and the clinical picture of PPH.

In five patients with congenital diaphragmatic hernia at least one episode of PPH was diagnosed. The average values of the ventilatory variables and prostanoid concentrations are presented in the table, and compared with the values in patients without episodes of PPH. In patients with right' to left shunting $\mathrm{AaDO}_{2}$, oxygenation index, and thromboxane $\mathrm{B}_{2}$ concentrations were significantly higher than in those without right to left shunting.

\section{Discussion}

Oxygenation of neonates with congenital diaphragmatic hernia in the perioperative period remains a challenging problem because of the combination of pulmonary hypoplasia and PPH.

Recently Hammerman and coworkers correlated the presence of $\mathrm{PPH}$ in neonates to increased concentrations of thromboxane $\mathrm{B}_{2}{ }^{3}$ The pulmonary vascular system of the patient with congenital diaphragmatic hernia differs from that of normal newborns and may overreact to different stimuli. ${ }^{6}$

In patients with congenital diaphragmatic hernia plasma concentrations of the vasoconstrictive metabolite thromboxane $B_{2}$ increased significantly during the surgical and anaesthetic procedure. If the pulmonary vascular system is still susceptible to vasoconstriction, it is obvious that in these cases pulmonary artery pressure may rise and right to left shunting may occur. In five out of seven patients thromboxane $B_{2}$ concentrations turned to baseline values at six hours postoperatively, showing that the rise of thromboxane $B_{2}$ is related to the operation.
In other words, the surgical procedure may provoke PPH in a 'susceptible' pulmonary vascular system.

Ventilatory variables have proved their use in prediction of survival in patients with congenital diaphragmatic hernia. ${ }^{1}$ The $\mathrm{AaDO}_{2}$ and the oxygenation index values are significantly higher in patients who have PPH. In these patients, concentrations of thromboxane $B_{2}$ have increased and might reflect an imbalance between vasodilation and vasoconstriction, dipping to vasoconstriction.

In conclusion: we have shown that during surgery there is activation of the arachidonic prostanoid cascade leading to a rise in thromboxane $B_{2}$ concentrations in patients with congenital diaphragmatic hernia. This may be an additional risk factor for right to left shunting postoperatively and it may be an argument for delayed surgery till the moment when the pulmonary vascular system has become 'stable'.

The authors thank Ko Hagoort for editing the manuscript and The authors thank Ko Hagoort for editing
Edith van der Ham for secretarial help.

The work was supported in part by a grant from Upjohn The work was supported in part
Medical Sciences Liaison Division.

1 Bohn D, Tamura M, Perrin D, Barker G, Rabinovitch M. Ventilatory predictors of pulmonary hypoplasia in congenital diaphragmatic hernia, confirmed by morphologic genital diaphragmatic hernia, confirmed

2 Stenmark KR, James SL, Voelkel NF, Toews WH, Reeves JT, Murphy RC. Leukotriene $\mathrm{C}_{4}$ and $\mathrm{D}_{4}$ in neonates with $\mathrm{JT}$, Murphy RC. Leukotriene $\mathrm{C}_{4}$ and $\mathrm{D}_{4}$ in neonates with
hypoxemia and pulmonary hypertension. $N$ Engl $\mathcal{f}$ Med 1983;309:77-80.

3 Hammerman C, Lass N, Strates E, Komar K, Bui KC. Prostanoids in neonates with persistent pulmonary hypertension. $\mathcal{F}$ Pediatr 1987;110:407-2.

4 Hazebroek FWJ, Tibboel D, Bos AP, et al. Congenital diaphragmatic hernia: impact of preoperative stabilization. A prospective pilot study in 13 patients. $\mathcal{I}$ Pediatr Surg 1988;23:1139-46.

5 Hageman JR, Adams MA, Gardner TH. Persistent pulmonary hypertension of the newborn. Am $\mathcal{J}$ Dis Child 1984;138:592-5.

6 Geggel RL, Murphy JD, Langleben D, Crone RK, Vacanti JP, Reid LM. Congenital diaphragmatic hernia: arterial structural changes and persistent pulmonary hypertension structural changes and persistent pulmonary hyp
after surgical repair. $\mathcal{F}$ Pediatr 1985;107:457-64. 